\title{
Numerical study on the effect of welding and heating treatments on strength of high strength steel column
}

\author{
J. Jianga,b*, W. Bao ${ }^{a, b}$, J. Liu ${ }^{a, b}$ and Z.Y. Peng,

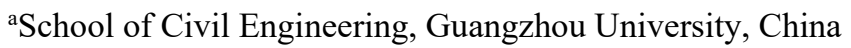 \\ ${ }^{\mathrm{b}}$ Complex Steel Structure Research Center of Guangdong Province, China \\ *corresponding author, E-mail address: jiangjin@gzhu.edu.cn
}

\begin{abstract}
High strength steel box columns are usually fabricated from steel slab by applying welding. The welding process can introduce residual stresses and geometric imperfections into the columns and influence the column strength. In this study, a numerical investigation on the behavior of high strength steel thin-walled box columns under the compression force was carried out. The welding processes were firstly simulated with commercial package ABAQUS in this study to find out the residual stress distributions in high strength steel box column. After that, the column behaviors under the compression were modelled with predefined field from the previous step. The effect of the welding process (including fluxcore arc welding and submerged arc welding), heating treatment (including preheating and post-weld heat treatment) and geometrical imperfection on the residual stress field and box column strength was investigated and discussed.
\end{abstract}

Keywords: Welding; heat treatment; high strength steel; column strength.

\section{Introduction}

Currently, most steel structures are made of mild steel for its satisfactory mechanical property and availability. In existing codes of practice, mild steel is well specified for structural application [1]. However, high strength steel (HSS) with yield strength larger than $460 \mathrm{MPa}$ has been an increasing interest in the usage for its merits in economy, aesthetics and safety [2]. The stress-strain behavior of HSS is different from mild steel such that HSS exhibits reduced ductility due to strain hardening after yielding. Furthermore, residual stress due to welding in HSS could be more serious than that in mild steel and might have a negative impact on its structural performance [3]. Uneven cooling of structural steel shapes and plates are the primary result of residual stresses within them. Welded built-up members exhibit tensile residual stresses in excess of the yield stress (in the region of the welded area) of the parent material. Due to the intense heat associated with flame-cutting, the material properties are significantly altered in these areas [4]. The thin HSS plate is likely to buckle locally in compression and therefore of significant importance for designing the thin-walled structures.

The local and overall buckling of columns for mild cold-formed steel structures has been extensively investigated $[5,6]$. In addition, some studies for the overall buckling of high strength steel can also be found [7, 8]. However, only a few studies have been reported on the interaction between the fabrication procedure and the buckling strength for high strength steel. The present paper is concerned with a numerical investigation for the impact of welding procedure on the buckling strength of thinwalled box columns made of high strength steel with yield stress of $690 \mathrm{MPa}$. A series of box columns with various welding treatments are analyzed.

\section{Modelling for welding residual stress}

\subsection{Overview}

Thermal cycles in the both of flux-core arc welding (FCAW) and submerged arc welding (SAW) processes inherently cause the metal to experience high temperature and to melt and 
solidify at the weld region, inducing nonlinear mechanical behavior such as residual stress as well as microstructure alternation in the weld region and HAZ. In this study, a coupled thermal-stress analysis is carried out for the both of welding processes with the determination of the resulting residual stress. For FCAW models, the multi-passes of weld will be lumped into two blocks for each corner of the box to reduce the computation cost. The heat source is applied though the DFLUX subroutine of the ABAQUS at two blocks for each corner. Large displacement effects have been considered in the modeling by including the non-linear geometry option, NLGEOM, in the ABAQUS. For SAW models, it is considered single pass welding for each corner of the box. The heat input for SAW process is also achieved by the DFLUX subroutine with different setting on the magnitude and coefficient of heat energy with FCAW process. For each welding process, three models corresponding to the specimens with 1) as-welded condition, 2) preheated box columns and 3) post-weld heated box columns are created. For the as-welded model, a consistent pre-defined temperature field of $30^{\circ} \mathrm{C}$ is given to the whole model. For the model corresponding to the preheating, $100^{\circ} \mathrm{C}$ is set for the area within $100 \mathrm{~mm}$ from the chord weld toe while $30^{\circ} \mathrm{C}$ is set for all other parts. It is input into the model as a predefined temperature field. It means that the preheating temperature error is ignored in the modelling and this predefined temperature field is modelled as uniform in the preheated area.

\subsection{Meshing, interaction and boundary condition}

ABAQUS includes general purposed linear and second order brick solid elements for heat transfer analysis and stress analysis [9]. In this study, a three-dimensional thermally coupled linear brick element (C3D8T) was used homogeneously throughout the entire model. The C3D8T element consists of a brick with eight nodes, and four degrees of freedom ( $x, y$ and $\mathrm{z}$ displacements $\{\mathrm{ux}, \mathrm{uy}, \mathrm{uz}\}$ and temperature) (Fig. 1). This element calculates displacements and temperatures using a linear integration method. As the weld would be added at the four corners of the built-up box column, an improved mesh is applied for the area close to the weldment. To make correctly input the residual stress field into the following column strength analysis model, the same meshing is used in the residual stress simulation and buckling simulation except the element type. In this analysis, a simplified treatment is assumed for the thermal interaction. All free surfaces (including outside surface, inner surface and two end surfaces) of the boxes are assumed for thermal convection and radiation. It means that all free surfaces from which the heat can dissipate into the air will have thermal convection and radiation for heat dissipation. The convection coefficient $\mathrm{h}$ is defined as 15 $\mathrm{W} / \mathrm{m}^{2} \mathrm{~K}$ and emissivity $\varepsilon$ is set as 0.2 .
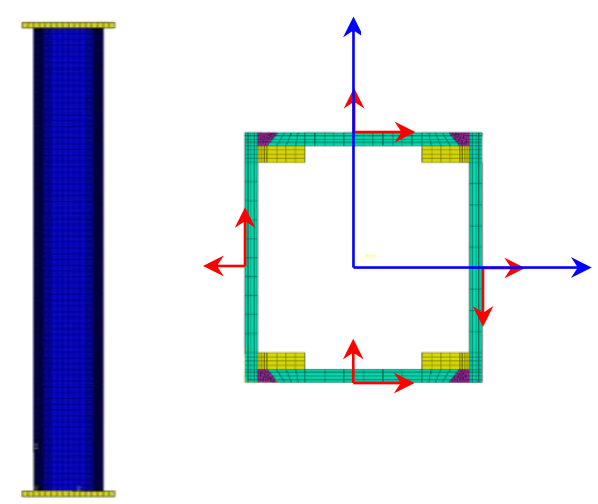

Fig. 1. The meshing of the model.

\subsection{The heat source model}

Since that the temperature field driven by the weld heat source is the dominant driving force for residual stress formation during the welding procedure, an accurate analysis of the thermal cycle is required to obtain accurate prediction of residual stress. Furthermore, the heating source is also the driving force for phase transformation, thermal strain and stress, and eventually residual stress formation. For the mathematical modelling of thermal cycles, it can be traced back to in the late 1930s when Rosenthal [10] firstly applied the Fourier law into moving heat sources. However, the main shortcoming of this solution is the misfit of temperature field near the fusion and heataffected zones. To accurately capture the temperature near the arc, Pavelic et al. [11] mentioned that the heat source should be distributed and proposed a Gaussion distribution of heat flux deposited on the surface of the work piece. Considering that the temperature gradient in front of the heat source is different from in the rear, a double ellipsoidal model of power density distribution was introduced by Goldak. In the double ellipsoidal model, the front half of the source is the quadrant of one ellipsoidal source and the rear half is the quadrant of another 
ellipsoid. To define the model, the fractions ff and fr of the heat deposited in the front and rear quadrants are needed such that of $f_{f}+f_{r}=2$. It was recommended by Goldak [12] that ff and fr should be set as 0.6 and 1.4, respectively. The power density distributions inside the front quadrant and the rear quadrant can be expressed as:

$$
\left\{\begin{array}{l}
q_{f}(x, y, z)=\frac{6 \sqrt{3} f_{f} Q}{a_{1} \cdot b \cdot c \pi \sqrt{\pi}} e^{\frac{-3 x^{2}}{a_{1}^{2}}} e^{\frac{-3 y^{2}}{b^{2}}} e^{\frac{-3 z^{2}}{c^{2}}} \\
q_{r}(x, y, z)=\frac{6 \sqrt{3} f_{r} Q}{a_{2} \cdot b \cdot c \pi \sqrt{\pi}} e^{\frac{-3 x^{2}}{a_{2}^{2}}} e^{\frac{-3 y^{2}}{b^{2}}} e^{\frac{-3 z^{2}}{c^{2}}}
\end{array}\right.
$$

where, $Q=\eta \cdot U \cdot I, \eta$ is the heat source efficiency, $U$ is the voltage of electric arc, $I$ is the current of electric arc and $a_{1}, a_{2}, b, c$ are ellipsoidal parameters.

In this analysis, the double ellipsoidal model is employed to predict the thermal and stress field during the welding. In order to automatically renew the weld filler elements as the welding process was carried out, a special FORTRAN program is developed to describe the moving of heat source. In the absence of better data, experience suggests that it is reasonable to take the distance in front of the heat source equal to one half the weld width and the distance behind the heat source equal to twice the width [12]. Table 1 list the heat model parameters used in both welding process.

Table 1.Heat source parameters for two welding process

\begin{tabular}{lccc}
\hline Welding process & & FCAW [13-14] & SAW \\
Net power $(\mathrm{kW})$ & & 4.4 & 80 \\
Heat coefficient & & 0.80 & 0.95 \\
Welding speed (mm/s) & & 2.6 & 10.0 \\
Heat source & $\mathrm{a}_{1}$ & 0.010 & 0.025 \\
geometrical & $\mathrm{a}_{2}$ & 0.020 & 0.050 \\
parameters & $\mathrm{b}$ & 0.010 & 0.032 \\
& $\mathrm{c}$ & 0.005 & 0.016 \\
\hline
\end{tabular}

\subsection{Modelling scenario}

There are two welding processes (FCAW and SAW) are chosen in this studied for the effect of welding methodology on the final residual stress field and column strength. FCAW is chosen because the flux cored arc welding process has become the most popular semiautomatic process for structural steel fabrication and erection. The FCAW offers two distinct advantages over shielded metal arc welding. First, the electrode is continuous so that it eliminates the built-in starts and stops that are inevitable with shielded metal arc welding. Another advantage is that FCAW increases in deposition rate and productivity [1314].

Table 2. Welding condition and geometry of the model

\begin{tabular}{|c|c|c|c|c|c|c|c|c|c|}
\hline \multirow[b]{2}{*}{ Group } & \multirow[b]{2}{*}{$\begin{array}{l}\text { Specimen } \\
\text { labelling }\end{array}$} & \multirow[b]{2}{*}{$\begin{array}{l}\text { Welding } \\
\text { method }\end{array}$} & \multirow[b]{2}{*}{$\begin{array}{l}\text { Welding } \\
\text { condition }\end{array}$} & \multicolumn{6}{|c|}{ Geometry } \\
\hline & & & & $\mathrm{D}(\mathrm{mm})$ & $\mathrm{d}(\mathrm{mm})$ & $\mathrm{t}(\mathrm{mm})$ & $\mathrm{L}(\mathrm{mm})$ & $\lambda$ & $\lambda_{0}$ \\
\hline \multirow{6}{*}{ A } & $A-F-1$ & \multirow{3}{*}{ FCAW } & As-welded & 100 & 76 & 12 & 1000 & 27.58 & 0.50 \\
\hline & $A-F-2$ & & Preheating & 100 & 76 & 12 & 1000 & 27.58 & 0.50 \\
\hline & $A-F-3$ & & PWHT & 100 & 76 & 12 & 1000 & 27.58 & 0.50 \\
\hline & A-S-1 & \multirow{3}{*}{ SAW } & As-welded & 100 & 76 & 12 & 1000 & 27.58 & 0.50 \\
\hline & A-S-2 & & Preheating & 100 & 76 & 12 & 1000 & 27.58 & 0.50 \\
\hline & $A-F-3$ & & PWHT & 100 & 76 & 12 & 1000 & 27.58 & 0.50 \\
\hline
\end{tabular}

Submerged arc welding (SAW) differs from other arc welding processes in that a layer of fusible granular material called flux is used for shielding the arc and the molten metal. Considering that it is frequently used in cases when welding path is simple and long enough, it is also included in this study to evaluate its extremely high heat input on the residual stress and column behavior. Table 2 gives the modelling scenario of this study.

To evaluate the heating effect on the residual stress magnitude and column strength, three models corresponding to 1) as-welded condition, 2) preheating before carrying out the welding and 3) post-weld heat treatment condition are created in this selection.

\section{1) As-welded columns}

To evaluate the heat treatment (preheating, post-weld heat treatment) on the residual stress field, the box columns welded at ambient temperature without any heat treatment is modelled and analyzed firstly as the benchmark model. It is classified to as-welded specimen, which means there is no preheating before the welding and no subsequent heat treatment operation following the welding.

2) Preheated columns

An effective way of preventing the cold cracking and minimize the residual stress is to preheat the weld area to higher temperature to delay the cooling of the welded joint. The minimum preheating temperature is depended on factors including the chemical composition of 
the base material, the thickness of work piece, the welding process and hydrogen content of the weld metal. There are two methods (Method A: Graphical determination and Method B: Computational determination) provided by EN1011-2:2001[15]. In this paper, Method B of EN1011-2, computational determination, is used to determine the minimum preheating temperature. The recommended minimum preheating temperatures for joints $12 \mathrm{~mm}$ RQT701 steel plate was found to be equal to $85^{\circ} \mathrm{C}$. However, in order to make the fabrication procedure easy to handle, a single preheating temperature of $100^{\circ} \mathrm{C}$ was applied to all preheated joints. It also should be noticed that overheated for Q\&T steel may be detrimental in the heat affected zone. Therefore, overheating should be avoided for the joint.

\section{3) Post-weld heat treated columns}

Post-weld heat treatment is often used to improve the properties of a welded structure. Two most common procedures used for PWHT are post heating and stress relieving [16]. The former one is used to minimize the potential for hydrogen induced cracking, which is normally happened when the temperature of the component is close to the ambient temperature. In this process, the steel shall not be allowed to cool to room temperature; instead, it should be immediately heated from the inter-pass temperature to the post heat temperature and held at this temperature for a design time. The latter one is used to reduce the stresses that remain locked in a structure as a consequence of manufacturing processes. Differentiated with post heating process, the component shall be allowed to fully cool down before stress relieving. The stress relieving PWHT will be studied in this paper for its effect on relieving the welding residual stress.

Since that the maximum temperature will not reach $\mathrm{Ac}_{1}$, the temperature at which austenitic transformation begins, PWHT is modelled by incorporating creep with temperature-dependent material properties. The Norton law should be followed during the soaking time for PWHT, which can be expressed as below:

$$
\varepsilon_{\mathrm{r}}=\mathrm{A} \sigma^{\mathrm{n}}
$$

where $\varepsilon_{\mathrm{r}}$ is the creep strain rate, $\sigma$ is von Mises equivalent stress, $A$ and $n$ are material constants and equal to $9.016 \mathrm{e}^{-27}$ and 10.286 respectively in this study, which are according to [17].

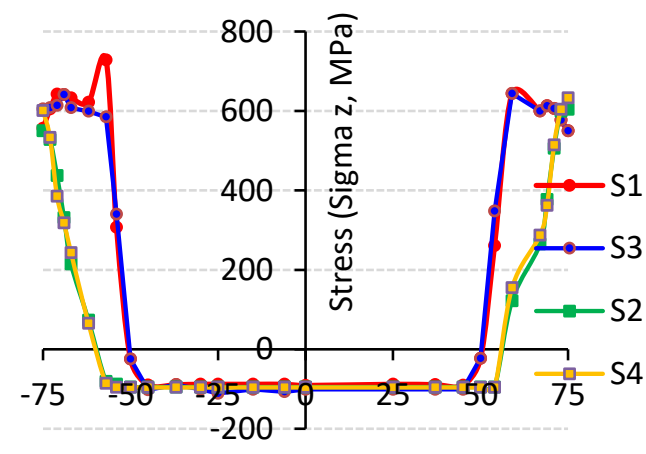

Distance from the center line $(\mathrm{mm})$

Fig. 2. S33 of as-welded column

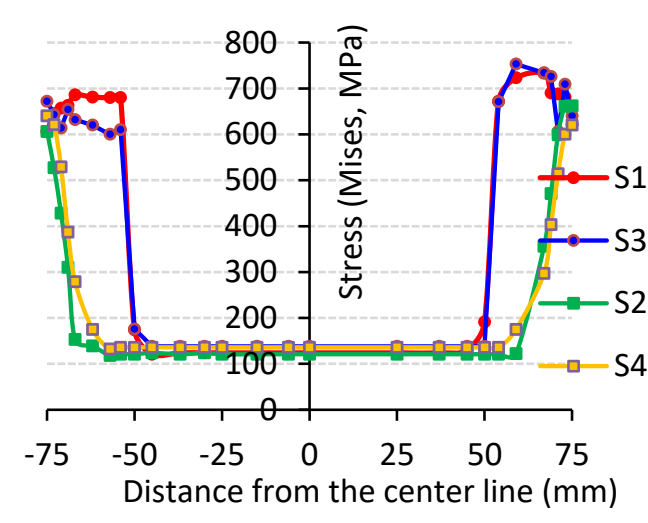

Fig. 3. Mises stress of as-welded column

\subsection{Modelling results and discuss}

The modelling results for FCAW case are selected for evaluating the heat treatment on the residual stress field in this section. Three models corresponding to as-welded columns, preheated columns and post-weld heated columns are chosen to study the impact of the heat treatment on the residual stress field. The stress along column length direction (S33) and Mises stress are selected for plotting against the local coordinate position (shown in Fig. 1).

Fig. 2 and Fig. 3 present the residual stress along column length direction (z direction) and Mises stress respectively, against the distance from the center lines. The figures show four curves, which are respectively representing the stress variation along four outside surface ( $\mathrm{S}$ 1: topside, S3: bottom, S2: left side, S4: right side, See Fig. 1). The curves show that, in the outside surface of the box column, the weld region and its' nearby has a tensile stress with its magnitude much higher than the other position in the base metal. It should be noted that the high tensile stress is only localized in $20 \mathrm{~mm}$ from the weld 
and stress drop quickly to compressive stress for the location outside this distance. Another finding is that the tensile stress is more uneven distributed on the outside surface of the box along S2 and S4 side. This phenomenon should be related to the weld configuration since the heat is transferred to S2 and S4 surface by the connection in the inner surface of the box (similar to "fillet weld" as to S2 and S4), while the heat energy is directly dissipated to S1 and $\mathrm{S} 3$ by heat conduction into base metal (similar to "butt weld as to S1 and S3).

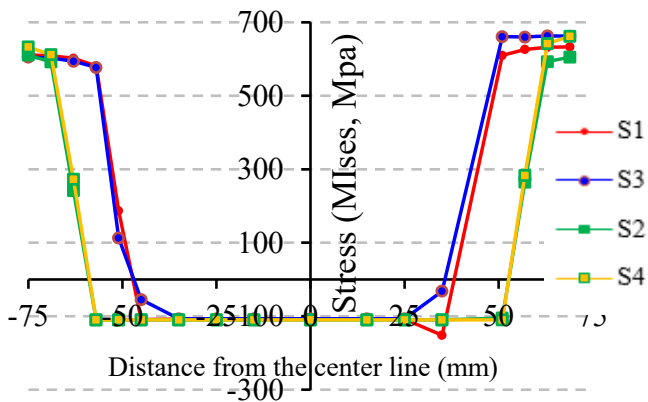

Fig. 4. S33 of preheated column

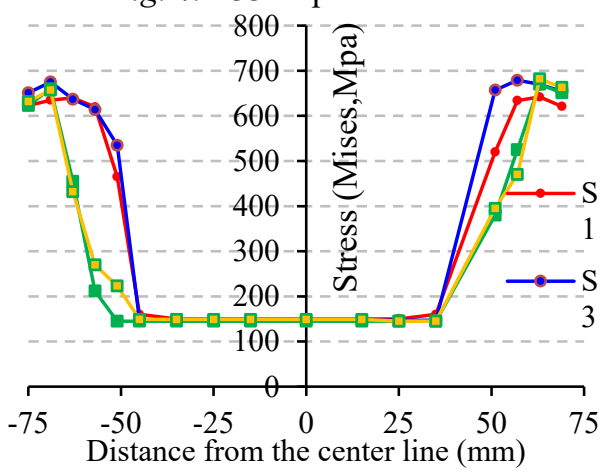

Fig. 5. Mises stress of preheated column

Fig. 4 and Fig. 5 show the welding residual stress along the column length direction ( $\mathrm{z}$ direction, S33) and Mises stress respectively for preheated column. Similar with stress distribution with as-welded columns can be found for preheated column: high tensile stress gathered in the vicinity of the weld and part of those areas is yielded. Compressive residual stress is mostly small in magnitude. By comparing Fig. 4 and Fig. 5 with Fig. 2 and Fig. 3 , it can be seen that preheating can reduce the highest tensile residual stress to approximately $13 \%$ from their original value (when the preheated temperature is $100^{\circ} \mathrm{C}$ ). Another observed influence of preheating is that it can slightly improve the stress gradient in the vicinity of the weld when comparing with aswelded column.
Fig. 6 and Fig. 7 show the distribution of residual stresses (S33 and Mises stress) with post-weld heat treatment. In the PWHT process, the temperature of the box columns was heated up to $600^{\circ} \mathrm{C}$ in the initial $1000 \mathrm{~s}$ and hold the temperature for 1.5 hours and then cooled to ambient temperature. It can be found that PWHT reduces nearly one third of the maximum tensile residual stress in the weld and HAZ area when compared with as-welded column. It means that in view of stress relieving effect, PWHT is more effective. The creep deformation during the soaking time can substantially reduce stress magnitude.

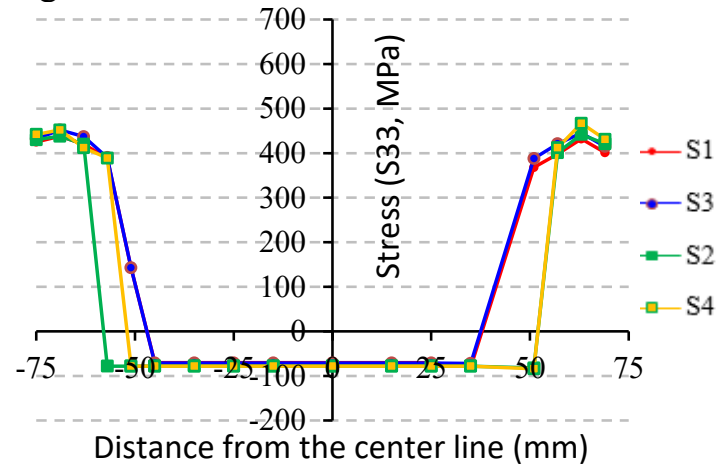

Fig. 6. S33 of PWHT column

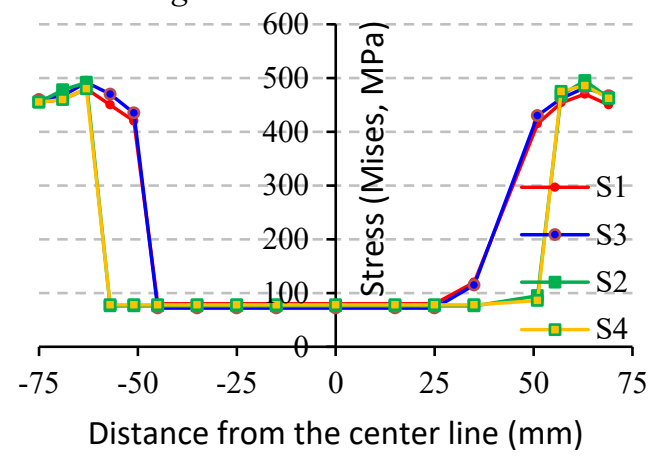

Fig. 7. Mises stress of preheated column

In this section, a comparative study between the residual stress fields due to FCAW and SAW is carried out. To avoid uncertainty of heating treatment, the as-welded models are selected for the comparison. As shown in Fig. 1, high tensile stress dominantly developed at the four corners of the box columns for both welding processes. Owing to the high net power input of the SAW process, the maximum tensile stress ( $\mathrm{S} 33, \mathrm{z}$ direction) is around $16 \%$ higher than that in FCAW model. Another finding is that the HAZ area in SAW model is wider than that in FCAW model. It means material deterioration is more serious happened in SAW model considering the face that the yielding stress would get a bit worse for Q\&T high strength steel after the welding. To 
make stress state self-balanced, a higher magnitude of compressive stress can be found in the outside surface of the SAW model. This cause the stress gradient in the transition area from HAZ to base metal very high, which would be weaken for its mechanical properties.

\section{Modelling for column buckling}

\subsection{Overview}

In this section, the built-up HSS columns behavior under the axially loading will be studied. Since the residual stress field obtained from Section 3 would be input into the buckling analysis as predefined field, the same meshing with residual stress simulation is used in this section except the element type is changed to $\mathrm{C} 3 \mathrm{D} 8 \mathrm{I}$, which is an 8-node linear brick element used for stress analysis [9]. To avoid the stress concentration effect for the axial loading in one end of the column, a reference point is created so that the load can be applied in the reference point. A coupling interaction between the reference point and the end plate is added so that the load can be averagely distributed into the end surface. For the reference point, both the translational and rotational degrees of freedoms are free so that load can be exerted directly on the movable end.

\subsection{Geometrical imperfection and residual stress}

The response of some structure depends strongly on the imperfections of the structure geometry, particularly if the buckling modes interact after buckling occurs. Hence, a geometrical imperfection would be assessed and used in the analysis. In this study, the degree of initial imperfection is specified as a percentage of steel plate thickness, which can be expressed as $0.3 \mathrm{t}(\mathrm{Py} / \mathrm{Pcr}) 0.5$ (Py: yield load, Pcr: the critical buckling load, t: steel plate thickness). In this study, it is modelled by multiplying deformation shape of eigenvalue buckling analysis by the coefficient of $3.6 \times 10-3$.The other method for incorporating geometrical imperfection is to introduce the out-of-plane deflection at midlength of the column based on the imperfection measurement. It was found that the two ways were not significant different for stub columns [18]. Meanwhile, a central bow of $1 / 1000$ of the member length covering unintentional load eccentricities is assumed in this study. The approach to define an imperfection in this paper involved two analysis runs with the same model definition: (a) In the first analysis run, an eigenvalue buckling analysis was performed on the "perfect" structure to establish probable collapse modes and to verify that the mesh discretizes those modes accurately. (b) In the second analysis run, an imperfection in the geometry was introduced by adding these buckling modes to the "perfect" geometry. After that, a geometrically nonlinear load displacement analysis of the structure was performed containing the imperfection using the Riks method to perform plastic buckling and post-buckling analyses of the column.
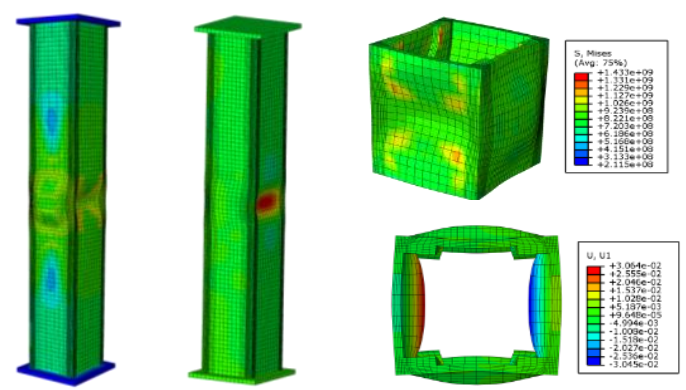

Fig. 8. Column deformation after local buckling

The welding-caused residual stress is incorporated in the analysis by importing the residual stress field from Section 3 as the predefined field for the buckling analysis.

\subsection{Modelling results}

The six model results are given in Table 3. The differences between modelling results with yielding load are shown in the table. The column deformation after the local buckling is shown as Fig. 8. It is observed that the local buckling load is close to the yielding load for as-welded models when FCAW is applied in the fabrication process. As to the preheating effect, it seems that no much improvement on the column strength. However, it should be noticed that PWHT can improve the column strength to some extent for both FCAW and SAW welding processes. Compared with FCAW process, the column strengths for three models corresponding to SAW process are all smaller. In another word, the influence of the welding residual stress in SAW is more serious (considering that the geometrical imperfections are all the same for the 6 models in the analysis).

Table 3.Modelling results for the box column

\begin{tabular}{ccccccc}
\hline & \multicolumn{3}{c}{ FCAW } & & & SAW \\
Specimen & As & Preheating & PWHT & As & Preheating & PWHT \\
& A-F-1 & A-F-2 & A-F-3 & A-S-1 & A-S-2 & A-F-3 \\
$P y(k N)$ & 3820 & 3820 & 3820 & 3820 & 3820 & 3820 \\
$P \mathrm{n} \mid(\mathrm{kN})$ & 3896 & 3973 & 4087 & 3591 & 3629 & 4049 \\
$P \mathrm{n} / \mathrm{Py}$ & 1.02 & 1.04 & 1.07 & 0.94 & 0.95 & 1.06 \\
\hline
\end{tabular}




\section{Conclusion}

A series of numerical models were carried out in this study to investigate the impact of the welding process and heating treatment on the high strength steel stub box columns. The welding residual stress field for both FCAW and SAW processes were obtained. By importing the residual stress and geometrical imperfections as the pre-defined input for the columns' buckling models, the column strengths with different welding process and heating treatment were obtained. The preliminary findings can be summarized below:

(1). High tensile residual stress dominantly developed at the four corners of the box columns for both FCAW and SAW welding processes. Owing to the high net power input of the SAW process, the maximum tensile stress ( $\mathrm{S} 33, \mathrm{z}$ direction) is around $16 \%$ higher than that in FCAW model.

(2). The HAZ area in SAW model is larger than that in FCAW model. Both preheating and PWHT can reduce the welding residual stress to some extent. However, in term of residual stressrelieving, the PWHT seems have a better effect than the preheating.

(3). The local buckling loads of the stub high strength steel box columns are close to the yielding loads. As to the preheating effect, it seems that no much improvement on the column strength. However, PWHT can improve the column strength to some extent for both FCAW and SAW welding processes.

\section{References}

[1] EC3, Design of steel structure-Part 1.1: general rules and rules for building, 1993, European Committee for Standardisation (CEN).

[2] Mochuzihi H, Yamashita T, and Fukasawa T. Application of HT780 high strength steel plate to structural member of super high-rise building: part 1 Development of high strength steel with heavy gauge and welding process. Proceedings of the 5th East Asia-Pacific Conference on Structural Engineering and Construction 1995; 2283-2288. Gold Coast.

[3] Masubuchi K. Analysis of welded structures: residual stresses, distortion, and their consequences International Series on Materials Science and Technology1980, Pergamon Press.
[4] Cheng, PY. Influence of Residual Stress and Heat Affected Zone on fatigue failure of welded piping joints, Ph.D Thesis of North Carolina State University, 2009.

[5] Usami T and Fukumoto Y. Local and overall buckling of welded box columns. Journal of the Structural Division 1982. Proceedings of the American Society of Civil Engineers, 108(ST3) :525-542.

[6] Liew JYR, Shanmugam NE and Lee SL. Local buckling of thin-walled steel box columns. ThinWalled Structures 1989; 8:119-145.

[7] Ban HY, Shi G, Shi YJ and Bradford MA. Experimental investigation of the overall buckling behaviour of $960 \mathrm{MPa}$ high strength steel columns. Journal of Construction Steel Research 2013; 88:256-266.

[8] Wang YB, Li GQ, Chen SW and Sun FF. Experimental and numerical study on the behaviour of axially compressed high strength steel box-columns. Engineering Structures 2014; 58:79-91.

[9] ABAQUS user manual. Version 6.13. Hobbit. Karlsson \& Sorensen Inc., USA.

[10] Rosenthal D. The theory of moving sources of heat and its application to metal treatments. Trans ASME 1976; 68:849-956.

[11] Pavelic V, Tanbakuchi R, Uyehara OA and Myers PS. Experimental and computed temperature histories in gas tungsten arc welding of thin plates. Welding Journal Research Supplement 1969; 48: 295-305.

[12] Goldak JA and Akhlaghi M. Computational Welding Mechanics, Springer, 2005.

[13] Lee CK, Chiew SP and Jiang J. 3D Residual stress modeling of welded high strength steel plate-to-plate joints. Journal of Constructional Steel Research 2013; 84: 94-104.

[14] Jiang J, Lee CK and Chiew SP. Residual stress and stress concentration effect of high strength steel box T-joints. Journal of Constructional Steel Research 2015; 105: 164-173.

[15]BS EN 1011-2:2001. WeldingRecommendations for welding of metallic materials. Part 2: Arc welding of ferritic steels, British Standard.

[16]Funderburk RS. Key concepts in welding engineering- Post weld heat treatment. Welding Innovation 1998; Volume. XV, No. 2.

[17]Zhang G, Zhou C and Xue J. Finite element analysis of high temperature piping creep under inner pressure and welding residual stress. Acta Metallurgica Sinica 2008; 44(10):1271-1276. 